\title{
FLOWER VISITING BATS AND DURIAN TREES: SPECIES RICHNESS AND POPULATION SIZE
}

\author{
NUR HAMZAH ZULFEMI MUHAMMAD ${ }^{1}$, SUEY YEE LOW ${ }^{1}$, SITI NOR SHAFFINAF \\ MOHAMAD SHUKRI ${ }^{1}$, AIDA HIDAYAH ABU SAMAH ${ }^{1}$, HASRUL ZAMAN HASSAN \\ BASRI $^{2}$, MUHAMMAD HAFFIDZIE MOHD SHUHAIMI ${ }^{2}$, HARIZAH NADIAH HAMZAH ${ }^{1}$, \\ MUHAMMAD AIDIL ZAHIDIN ${ }^{2,3}$, MUHAMMAD SYAMSUL AZNAN ARIFFIN ${ }^{2}$ AND \\ MOHAMED NOR ZALIPAH ${ }^{1 *}$
}

${ }^{1}$ Faculty of Sciences and Marine Environmental, ${ }^{2}$ Institute of Tropical Biodiversity and Sustainable Development, Universiti Malaysia Terengganu, 21030, Kuala Nerus, Terengganu, Malaysia. ${ }^{3}$ School of Medical Science, Universiti Sains Malaysia (Health Campus), 16150 Kubang Kerian, Kelantan, Malaysia.

*Corresponding author: zalipah@umt.edu.my

Submitted final draft: 30 August $2020 \quad$ Accepted: 4 October $2020 \quad$ http://doi.org/10.46754/jssm.2021.07.006

\begin{abstract}
Bats play a vital role in the pollination of durian tree flowers, but its population is shrinking due to climate change and excessive hunting. This study tries to determine the bat species richness and population size in a durian orchard. A simple mark-recapture experiment was conducted using mist nets to tag flower-visiting bats of two durian species - Durio zibethinus and D. lowianus - at the Malaysian Agricultural Research and Development Institute orchard in Jerangau, Terengganu, Peninsular Malaysia. The characteristics and species of captured bats were recorded to estimate the population size using the Schnabel formula for a closed population. A total of 137 individuals were captured, comprising four species - Eonycteris spelaea, Cynopterus brachyotis, C. horsefieldii, and Scotophilus kuhlii. E. spelaea was the most abundant species, representing $53 \%$ of the total captured individuals. The estimated population size of the bats with $95 \%$ confident interval was 1,110 individuals per hectare, with an upper range of 10,882 individuals. The large population of bats visiting the durian orchard may indicate the importance of this area as a feeding site, particularly for E. spelaea. This further indicates the significant contribution of these flower-visiting bats in the pollination of durian flowers.
\end{abstract}

Keywords: Eonycteris spelaea, Durio, population size, pollinating agents, Peninsular Malaysia.

\section{Introduction}

The genus Durio consists of 29 species, in which 23 are known to occur in Malaysia (Idris, 2011). The trees of this genus produce thorny fruits with a pungent smell and large seeds enclosed in fleshy aril. From the 23 species found in Malaysia, at least nine are known to produce edible fruits. Despite having a pungent smell, the durian is a favourite fruit in Southeast Asia. Malaysia, for example, has been reported to consume up to 349,000 tonnes of durian in 2014, with an average of $11.2 \mathrm{~kg}$ per individual (Mokhzani, 2017). Although believed to originate from Peninsular Malaysia and Borneo, durian trees have been propagated throughout tropical Asia - from Sri Lanka to Papua New Guinea, with some also being cultivated in Hawaii, the United
States, and northern Australia. The Durio tree is characterized by its ephemeral mass flowering and chiropterophilous syndrome, such as nocturnal anthesis, production of a musky smell from sulfur components (Willmer, 2011), and cauliflory appearing in either solitary, or most commonly in fascicled or in few-flowered cymes (Idris, 2011). The flowering usually occurs at night during the dry season, which may last for 10 to 14 days (Paull \& Duarte, 2012). Due to its seasonality, there is high demand for durians, leading to a high economic value in cultivating the fruit. In 2018, it was reported that Malaysia and Thailand have exported durians worth approximately US\$550 million to China, which seems to be the biggest and most lucrative market (Bernama, 2019; Neo, 2019). 
The most important factor for durian trees to bear fruit is the availability of pollinating agents as the trees could not pollinate themselves due to self-incompatibility (Lim \& Luders, 1998; Bumrungsri et al., 2009). Previous studies have reported small pteropodid bats (Bumrungsri et al., 2009; Acharya et al., 2015; Stewart \& Dudash, 2017) and an island flying fox (Pteropus hypomelanus) (Aziz et al., 2017) as the main pollinators of the most cultivated durian species, Durio zibethinus, in Thailand and Malaysia. As the abundance of pollinators has been observed to have direct impact on fruiting success of durian trees (Junqueira \& Augusto, 2017; Forrest \& MacInnis, 2019), estimating the bat population size is important to monitor and ensure a high yield in orchards

Despite playing a vital role in pollination, bat numbers have been reported to be decreasing from human activities, most notably is the hunting and killing of these creatures as they are wrongly perceived as pests and diseasescarriers (Aziz et al., 2016). Besides that, climate change also contributes to a reduction of the bat population. Bats are sensitive to increments in environmental temperature and the loss of watering holes will cause them to suffer dehydration, which leads to death (Sherwin et al., 2013). This study aims to identify the species richness and abundance of bats in a durian orchard, not only to highlight their economic benefits as a pollinator of durian trees, but also to indirectly contribute to their conservation in Malaysia.

\section{Materials and Methods}

\section{Study Site}

The study was conducted at the Malaysian Agricultural Research and Development Institute (Mardi) research station in Jerangau (448'370”N 1038'680”E), Hulu Terengganu, in Terengganu state of Peninsular Malaysia (Figure 1). The station was established to conduct research and development in food, agriculture and agro-based industries. Apart from office

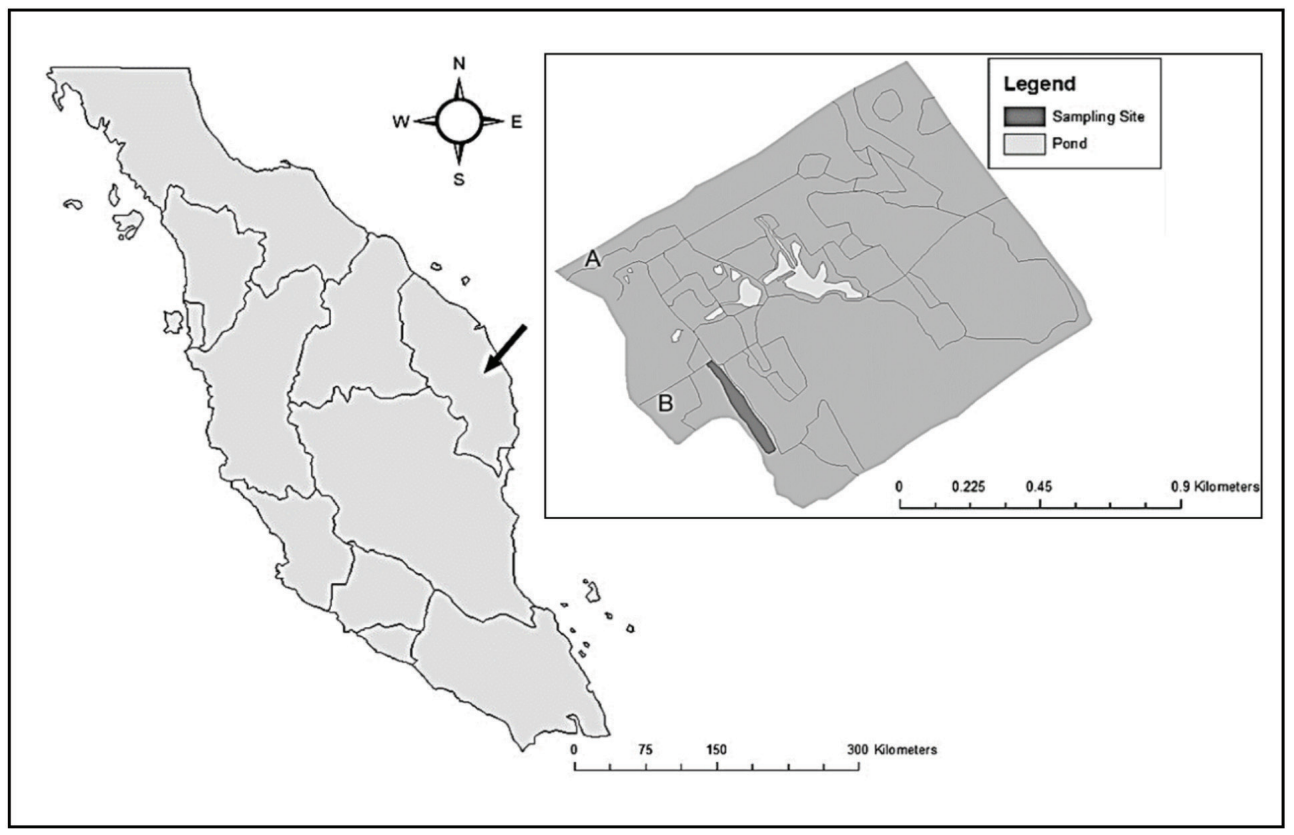

Figure 1: Map showing the location of the Malaysian Agricultural Research and Development Institute research station in Jerangau, Hulu Terengganu, Terengganu, Malaysia. Inset map shows the location of the durian trees near the office (A) and staff quarters (B), where the mist nettings were constructed for the markrecapture experiment of bat pollinators 
buildings, laboratories and staff quarters, the site also had a 145-ha orchard planted with various fruit crops, such as durians (Durio spp.), bananas (Musa spp.), mangosteens (Garcina mangostana), papayas (Carica papaya) and rambutans (Nephelium lappaceum).

Eight durian species were planted in the orchard, mostly D. zibethinus, which is a popular species cultivated in Peninsular Malaysia. Durian trees mostly exhibited the "big-bang flowering strategy" (Gentry, 1974), where they flower massively between four and six weeks in a year (Lim \& Luders, 1998). All durian trees in the study area had been observed to flower simultaneously between March and April (Zainal Abidin, personal communication, July 22, 2019).

This study focused on the trees of two Durio species - D. zibethinus and D. lowianus (Figure 2). The flowers of D. zibethinus have cream or white petals, whereas D. lowianus produced bright pinkish-red flowers. The wild-type $D$. lowianus trees were native to Peninsular Malaysia, but this species had been cultivated and semi-domesticated in other regions, where fruits of varying quality had been produced (Idris, 2011). For both durian species, anthesis (blooming) usually occurred in the evening and at night, characterised by the splitting of the epicalyx to reveal the petals and protruding stamen (Lim \& Luders, 1998). The fully-bloomed flowers could be observed from 1800 hours onwards, and the stamens and petals would be shed the next morning - all being typical features of bat-pollinated flowers (Willmer, 2011). For some flowers, however, it was observed that the petals did not shed, but became wilted and dried on the branch, indicating the end of the anthesis period.

\section{Mark-recapture Experiment}

The mark-recapture of pollinating bats was carried out in the flowering season throughout April 2018. A total of eight to 12 mist nets (4 $\mathrm{m}$ in height and $9 \mathrm{~m}$ in width) were set up in front of flowering D. zibethinus trees to capture flower-visiting bats as described by Bumrungsri et al. (2009); Acharya et al. (2015) and Steward and Dudash (2017). Three sampling sessions were carried out for six days each between April 5 and 21. For D. lowianus trees, five to nine mist nets were set up for two sampling sessions of four days each, all conducted from April 20 to 28.

The experiment was conducted on eight $D$. zibethinus trees and $10 \mathrm{D}$. lowianus trees planted in a 0.5 -ha area. The nets were set up at 1800 hours and taken down at 0700 hours the next day. They were checked as regularly as possible throughout the night, usually between 1900 to

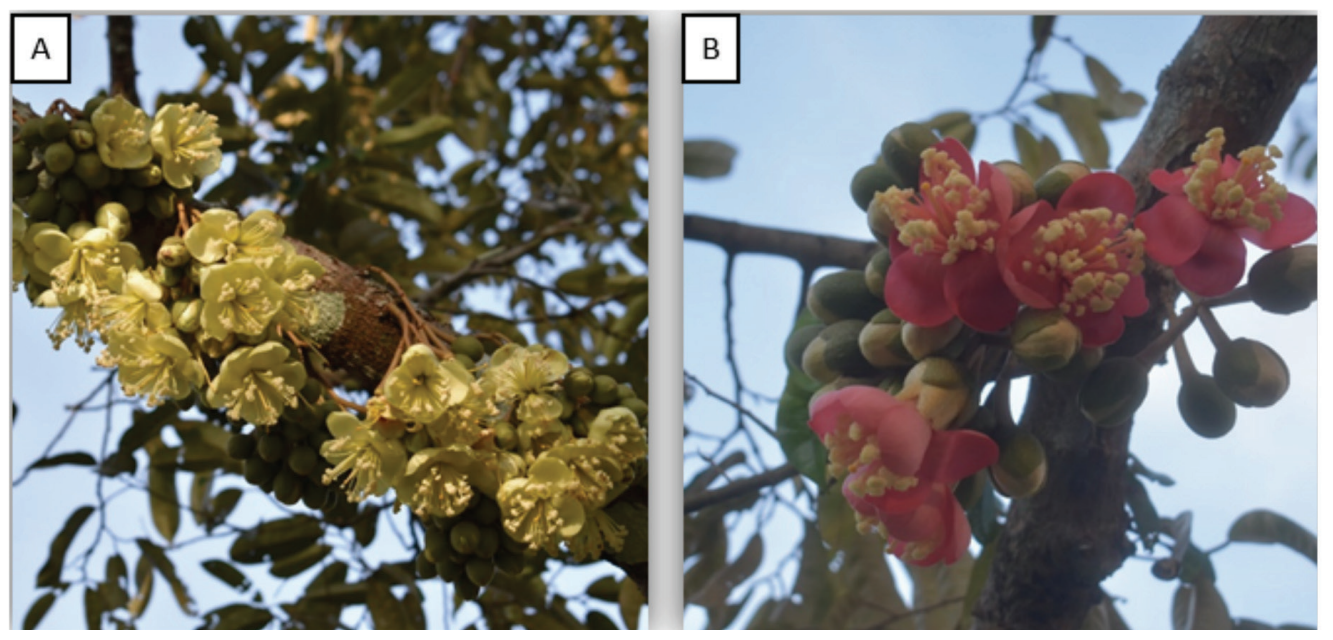

Figure 2: Fully-bloomed flowers of A) Durio zibethinus and B) D. lowianus 
2100 hours, 2300 to 0100 hours the next day, and between 0600 to 0700 hours. Trapped bats were measured and catalogued for identification according to Kingston et al. (2006). Non-toxic nail polish was applied to the nail of the bats' hind leg as a marker to identify the individual if it was recaptured in other sessions. Bats netted during the night were released immediately, but individuals caught at dawn (between 0600 and 0700 hours) were kept in a in individual cloth bags in a dark place before being released at sunset (usually after 2000 hours). Throughout this period, the bats were supplied with sugar syrup to replenish their energy.

\section{Population Size Estimation}

The population size was estimated using the Schnabel formula for the closed population with multiple marking events (Krebs, 1999). To calculate the population size, netted bats were pooled into sampling events according to their capture time, which were either 1900 to 0100 hours or 0100 to 0700 hours, in accordance with the foraging times of pteropodid bats visiting their food plant species (Steward et al., 2014). An individual was considered a recapture only if it was caught later in a different sampling event. In this study, calculations were made for four sampling sessions, with three sessions of four sampling events (in three consecutive sampling days) and a session of six sampling events (in four consecutive sampling days). For the Schnabel estimator, the upper and lower limits of the $95 \%$ confident intervals (CI) were obtained from the Poisson distribution when the total recapture recorded was $<50$. Regression analysis was performed to test the linear relationship between marked animals in samples $\left(\mathrm{R} / \mathrm{C}_{t}\right)$ and the number of marked animals atlarge $\left(M_{t}\right)$. A positive linear relationship between two variables indicated that the assumptions of the Schnabel method had been met.

\section{Results and Discussion}

\section{Species Richness and Abundance}

In this study, 137 bats from four species were captured visiting the durian trees (Figure 3). Eonycteris spelaea (cave nectar bat) comprised the highest number of individual species netted $(2=81.540, \mathrm{df}=3, p<0.05)$ making up $53 \%$ of the total individuals captured (Figure 4). Meanwhile, the lowest number of individual species netted was Cynopterus horsfieldii (Horsfield's fruit bat), with only two individuals (1\%) captured.

From the total 150 captures recorded, the majority (68 \%) was recorded from nettings at $D$. lowianus trees (Figure 5). For both durian species, E. spelaea was the most pollinator captured, with 23 individuals caught at $D$. zibethinus trees and 55 individuals at $D$. lowianus trees. From the 18 sampling events, the mean (+SE) capture rate (ind/net) was $0.909+0.194$ (Figure 6). Even though trappings were conducted on eight sampling events only for D. lowianus trees compared to 12 events for D. zibethinus, the capture rate was significantly higher (independent sample t-test, $t_{(8)}=-3.140$, $p=0.014$ ) for $D$. lowianus trees $(1.875+0.439)$ than $D$. zibethinus trees $(0.446+0.118)$.
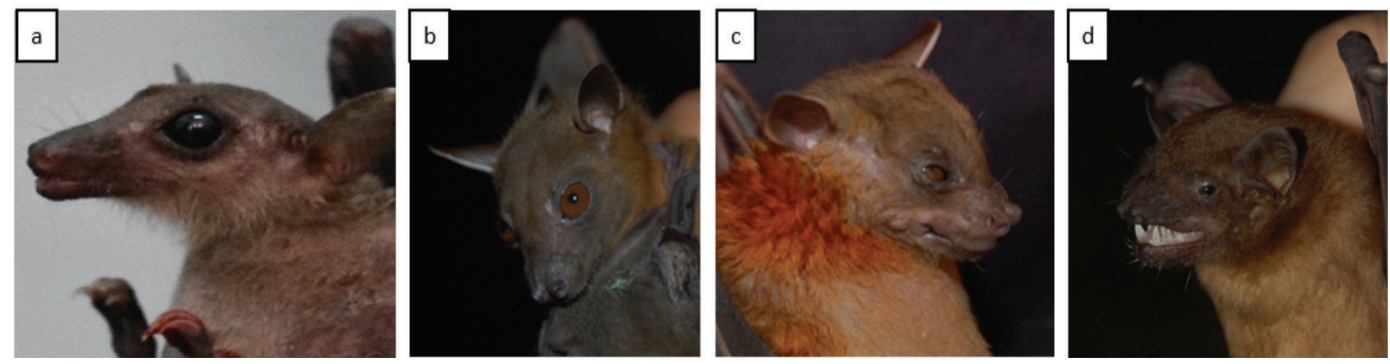

Figure 3: Durian tree pollinators caught in the study area. a) Eonycteris spelaea, b) Cynopterus brachyotis, c) Cynopterus horsfieldii and d) Scotophilus kuhlii 


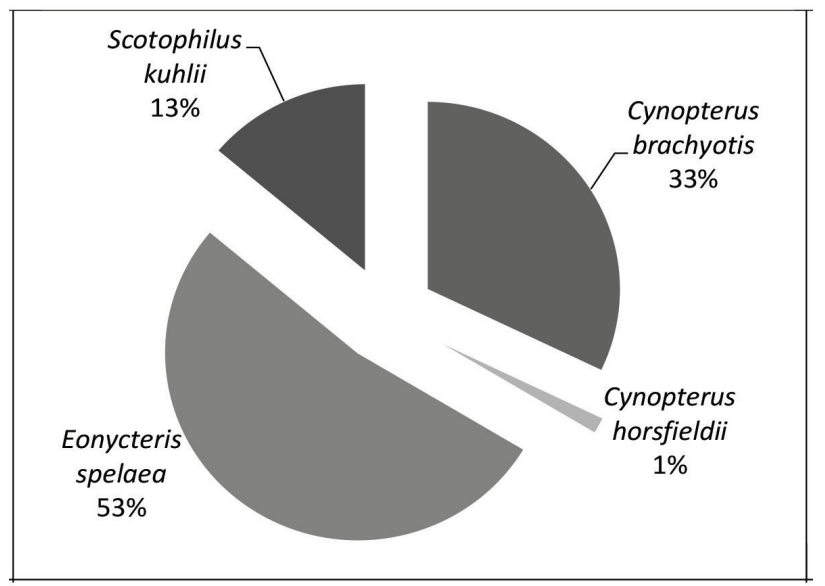

Figure 4: Species composition of bat individuals captured (\%) while visiting durian trees at the Malaysian Agricultural Research and Development Institute research station in Jerangau, Terengganu, Malaysia

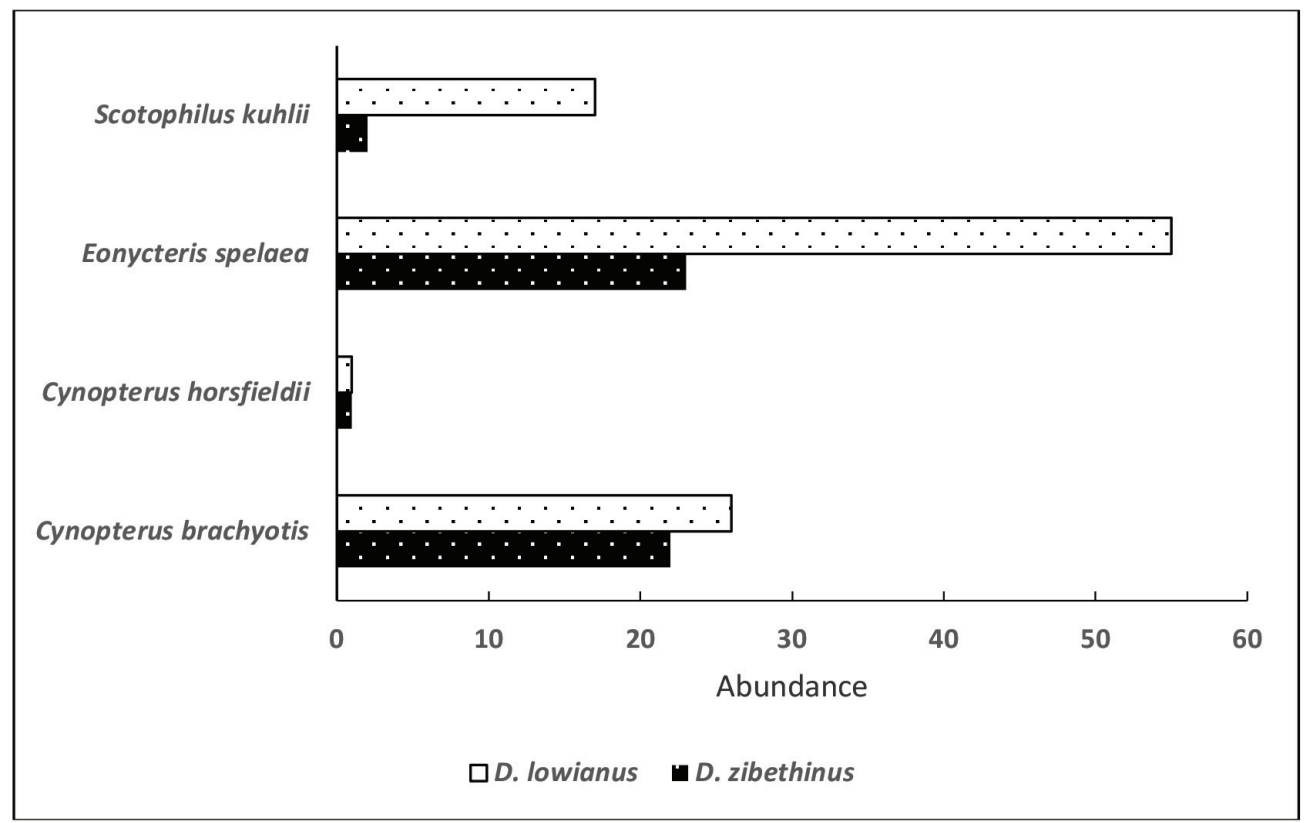

Figure 5: Number of bat captures according to species at Durio lowianus and D. zibethinus trees

Among the four bat species observed, $E$. spelaea was the most dominant pollinator for both durian species. This was because E. spelaea is a true nectarivorous bat, which mainly fed on nectar (Thavry et al., 2017). The head of this bat had a projected shape and is equipped with narrow muzzles and a long tongue to access the floral nectar (which was usually positioned deep inside a flower) compared to flat-faced frugivorous bats (Freeman, 1995). E. spelaea had been described as a generalist nectarivore that could switch their source of nectar from steady-state flowering plants like the banana tree, to big-bang flowering plants like durian trees during the flowering season (Stewart \& Dudash, 2018). While feeding on the nectar of flowers, E. spelaea would collect the pollen grains on its face and body. These pollen grains 


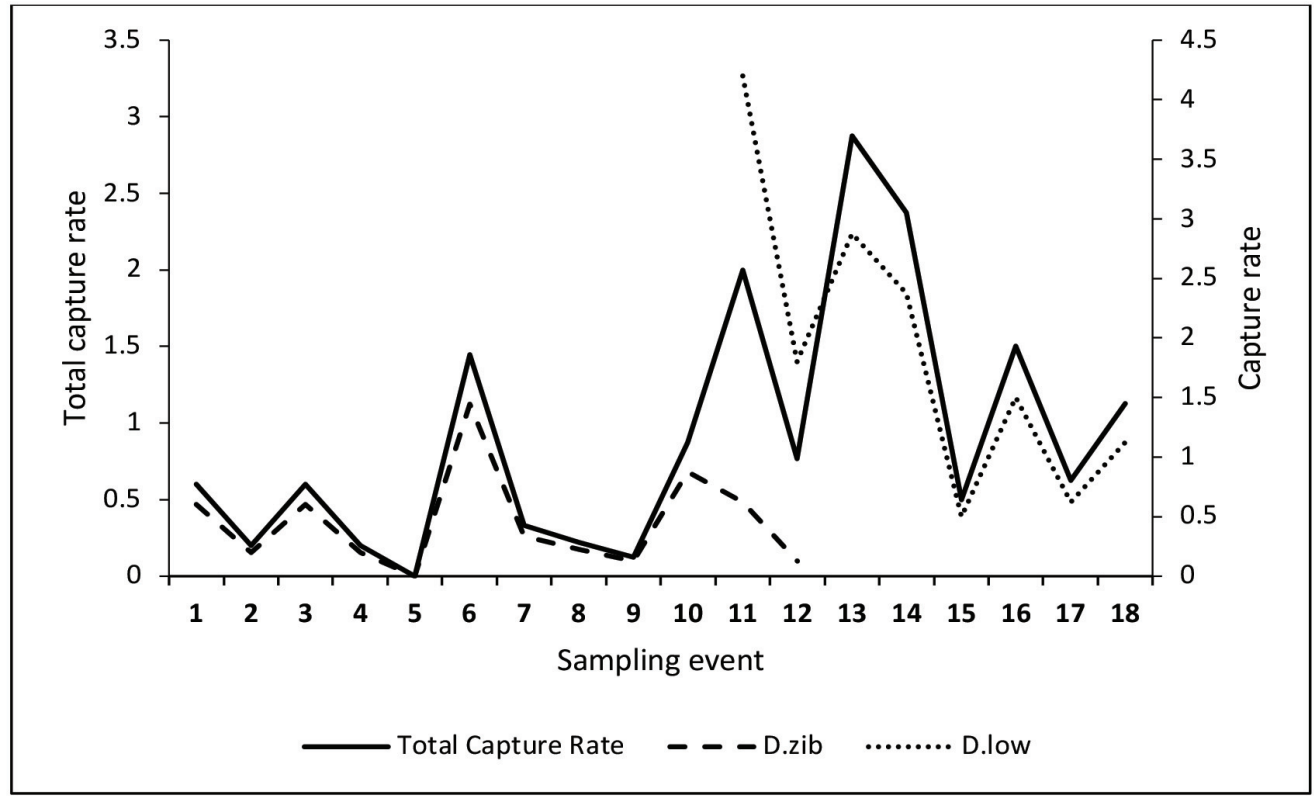

Figure 6: Capture rate of pollinating bats (ind/net) recorded according to durian tree species (D.zib $=$ Durio zibethinus, D.low $=$ Durio lowianus $)$. Nettings were conducted on both durian species on the $11^{\text {th }}$ and $12^{\text {th }}$ sampling event only

would be propagated throughout a wide area when the mammals move on to feed on other flowers, pollinating other trees in the process. In Thailand (Bumrungsri et al., 2009; Acharya et al., 2015) and Malaysia (Aziz et al., 2017), E. spelaea was recorded as a frequent visitor of $D$. zibethinus flowers. However, this study seemed to be the first to document E. spelaea and other bat species visiting flowering $D$. lowianus trees since there were no reports on pollinating agents of this wild durian.

There were three species of true nectarivorous bats in Malaysia (Start \& Marshall, 1976). However, E. spelaea was the only one that could be found in the country's primary forests and agricultural areas (Francis, 2008). The other two species - Macroglossus minimus and $M$. sobrinus - were forest-dependent species found in coastal and inland habitats, respectively (Marshall, 1983). Although E. spelaea is a cave-dwelling bat, to our knowledge, there were no known caves nearby the sampling site. Therefore it was possible that this bat had come from a distant area, since it could travel as far as
$60 \mathrm{~km}$ away from its roosting cave in a single night to feed (Start, 1974).

Besides that, the two frugivorous species - C. brachyotis and C. horsfieldii - were also recorded visiting both flowering $D$. zibethinus and $D$. lowianus trees. These two species were commonly found in areas with human activity (Kingston et al., 2006), and could live in caves, trees, rock shelters, drains and culverts (Shafie et al., 2011). Even though their diet consisted of a variety of fruits, they were also known to consume nectar (Raghuram et al., 2006; Smith \& Xie, 2008). Thus, this also made them potential pollinators of durian trees, as they might collect (Low et al., in prep.) and propagate pollen grains while visiting the durian flowers.

Scotophilus kuhlii was the only insectivorous species recorded in this study. This species could be found in a wide range of habitats, such as primary and secondary forests, and rural and urban dwellings (Kingston et al., 2006). The sampling site was surrounded by oil palm plantations and human settlements, which might act as roosting sites for this species. 
Furthermore, the lack of insectivorous bat species recorded in this study was not surprising since most insect-eating bats were inclined to inhabit forested areas than agricultural sites, where its food source was more abundant (Medellin et al., 2000).

Although they played no role in the pollination of durian trees, this insectivorous bat species might still contribute to the pollination process by reducing the competition between bats and insects for nectar by suppressing the insect population (Kunz et al., 2011). Bats were more capable and effective in propagating a large quantity of pollen grains compared to insects (Fleming et al., 2009; Bumrungsri et al., 2009). With more nectar available in the flowers due to fewer insect visitors, there would be a higher flower visitation rate by bats, thus raising the amount of pollen transfer between the flowers.

Furthermore, insectivorous bats could also contribute to pollination through contact with flowers when preying on feeding insects. Pollination by an insectivorous bat species, Antrozous pallidus (pallid bat), had been reported among the columnar cactus (Pachycereus pringlei) in the Sonoran desert of Mexico (Frick et al., 2013). A study had recorded videos of the bat making contact with $P$. pringlei flowers although this bat typically ate large arthropods, such as crickets and scorpions (Hermanson \& O'Shea, 1983). In this study, however, there was no observation of any physical contact between S. kuhlii and the durian flowers while preying on insects, thus further study would be needed to understand their activities near the durian trees.

In terms of abundance, a higher number of bat individuals recorded for $D$. lowianus could be due to the distribution of the trees, in which D. lowianus trees were planted closer to each other compared to D. zibethinus trees. Due to the close distance, it was more convenient for the bats to feed on D. lowianus flowers as less energy would be required to travel for food (Karasov, 1992). Not only that, the closer distance between the trees might also provide canopy cover as a natural protection to the bats from predators (Russo et al., 2007) like owls and kestrels (Speakman, 1991; Lesinski et al., 2009). Furthermore, the flowering of D. zibethinus trees had occurred earlier, in which many flowers (from more than hundreds of trees) were available for the bats to forage on a particular night. The flowers of $D$. lowianus, on the other hand, started to bloom after $D$. zibethinus ceased its flowering. Therefore, bat visitations would be concentrated on the available $D$. lowianus flowers (from about only 30 trees in a 0.404 ha area) towards the end of our sampling session.

\section{Bat Population Size}

There were 13 recaptures (9 \%) from 12 individuals recorded from the total of 150

Table 1: Bat population size estimated using the Schnabel (1982) method. Numbers in parentheses indicate a lower and upper range of the population estimated at $95 \%$ confidence interval. Regression analyses were conducted to test the adherence to a closed population assumption

\begin{tabular}{lcc}
\hline Sampling session & Population size (N) & Regression Analysis \\
\hline $5^{\text {th }}-7^{\text {th }}$ April & 88.00 & $\mathrm{y}=0.024 \mathrm{x}, \mathrm{r}^{2}=0.550, t=1.941, p=0.192$, \\
& $(16.53-1725.49)$ & \\
$12^{\text {th }}-14^{\text {th }}$ April & 89.00 & $\mathrm{y}=0.024 \mathrm{x}, \mathrm{r}^{2}=0.243, t=0.849, p=0.486$ \\
& $(16.72-1745.10)$ & \\
$19^{\text {th }}-21^{\text {th }}$ April & 555.00 & $\mathrm{y}=0.003 \mathrm{x}, \mathrm{r}^{2}=0.929, t=6.519, p=0.025^{*}$ \\
$25^{\text {th }}-28^{\text {th }}$ April & $(104.26-10882.35)$ & \\
& 254.43 & $\mathrm{y}=0.004 \mathrm{x}, \mathrm{r}^{2}=0.046, t=0.565, p=0.603$ \\
\hline
\end{tabular}

*significant at $p=0.05$ 
captures. Recaptures involved only two species; E. spelaea (seven individuals) and C. brachyotis (five individuals) with one of E. spelaea being recaptured twice. Only the population size estimated during the third sampling event was observed to fulfil the closed population assumption from the regression analyses at $p=0.05$ (Table 1). The highest population size estimated was 555 individuals in the third session, with the range of 104 to 10,882 individuals. For the first two sessions, the population estimated were approximately 90 individuals, while the final session recorded almost half of the population size estimated for the third session.

The low recapture value of individuals recorded in this study (only 9\%) had made it unable to estimate population size significantly - only the estimation in the third sampling session was found to be significant, which was about 1110/ha. The low number of recaptures, however, was comparable to other studies conducted in neo-tropical agricultural areas. For example, Bernard \& Fenton (2003) and Medina et al. (2007) both reported approximately four per cent of recaptures. Nevertheless, the capturing of bats in/near roosting sites would frequently result in higher recapture rates [eg. Gaisler \& Chytil (2002) recorded approximately $20 \%$ value, while Papadatou et al. (2012) recorded $50 \%$ or more recaptures for four of the five European tree-roosting bat species they monitored]. Although estimating population size of highly mobile taxa such as bats was challenging, the estimation provided in this study nevertheless indicated high chances for pollen transfer to occur from a high abundance of bats visiting the durian orchard.

Compared with insects, large-bodied and high mobility vertebrate pollinators could carry larger loads of pollen and travel considerable distances to promote cross-pollination. Bats, for example, provided great mobility for pollen propagation within and among populations (Horner et al., 1998; Molina-Freaner et al., 2003) in at least 67 families of angiosperms worldwide (Fleming et al., 2009; Kunz et al., 2011). Not only that, bats were also known to transport greater amounts of pollen grains compared to other vertebrate pollinators like birds (Law \& Lean 1999; Muchhala, 2006; Muchhala, 2007). The most commonly caught species in this study, E. spelaea, is known to travel long distances in a night from their roosting cave to the feeding sites (Start \& Marshall, 1976). By travelling long distances to forage, however, required high energy investment compared with the amount of nectar produced by flowers over a given time. Bats consequently must visit numerous flowers in numerous trees to feed on as much nectar as possible, thus promoting cross-pollination (Acharya et al., 2015).

\section{Conclusion}

In conclusion, four bat species were caught visiting the durian trees, including the nonphytophagous bat species, Scotophilus kuhlii. Nevertheless E. spelaea, a true nectar feeder, was the dominant species caught, further confirming its significant role in the pollination of the durian trees. The other bat species, however, although low in numbers, might also play a vital role as pollinating agents for durian trees through contact with the flowers (stigma and anthers) while feeding on nectar, or while preying on insects that visited the durian flowers. Thus, the conservation of these bat species would also be crucial. This simple mark recapture experiment in front of flowering durian trees thus had provided important information on the assemblages and population size of the bats in a durian orchard, which could be used as an indicator to ensure a good yield of the "king" of fruits.

\section{Acknowledgements}

This research was funded by Nagao Natural Environment Foundation. We would like to thank Prof. Dato' Dr. Mohd Tajuddin Abdullah of Universiti Malaysia Terengganu for his encouragement and continuous support in this project, and the School of Marine and Environmental Sciences (now known as Faculty 
of Science and Marine Environment) for logistical support and equipment to conduct this research. Permission to conduct the fieldwork was granted by Mardi Terengganu. We like to express our gratitude to Muhamad Zaki Mohamed Nor, then head of Mardi Jerangau, and his staff for assisting in this study.

\section{References}

Acharya, P. R., Racey, P. A., Sotthibandhu, S., \& Bumrungsri, S. (2015). Feeding behaviour of the dawn bat (Eonycteris spelaea) promotes cross pollination of economically important plants in Southeast Asia. Journal of Pollination Ecology, 15(7), 44-50.

Aziz, S. A., Clements, G. R., McConkey, K. R., Srithongchuay, T., Pathil, S., Abu Yazid, M. N. M., Campos-Arciez, A., Forget, P., \& Bumrungsri, D. (2017). Pollination by the locally endangered island flying for (Pteropus hypomelanus) enhances fruit production of the economically important durian (Durio zibenthinus). Ecology and Evolution, 7(21), 8670-8684.

Aziz, S. A., Olival, K. J., Bumrungsri, S., Richards, G. C., \& Racey, P. A. (2016). The conflict between pteropodid bats and fruit growers: Species, legislation and mitigation. In C. C. Voigt, \& T. Kingston (Eds.), Bats in the anthropocene: Conservation of Bats in a Changing World (pp.377-426). Springer.

Bernama (2019, June 17). Salahuddin: Frozen durian exports to China to reach 1,00 metric tonnes monthly. The New Straits Times. https://www.nst.com.my/news/ nation/2019/06/497026/salahuddin-frozendurian-exports-china-reach-1000-metrictonnes-monthly

Bernard, E., \& Fenton, B. (2003). Bat mobility and roosts in a fragmented landscape in Central Amazonia, Brazil. Biotropica, 35(2), 262-277.

Bumrungsri, S., Sripaoraya, E., Chongsiri, T., Sridith, K., \& Racey, P. A. (2009). The pollination ecology of durian (Durio zibethinus, Bombacaceae) in southern Thailand. Journal of Tropical Ecology, 25, 85-92.

Fleming, T. H., Geiselman, C., \& Kress, W. J. (2009). The evolution of bat pollination: A phylogenetic perspective. Annals of Botany, 104, 1017-1043.

Francis, C. M. (2008). A field guide to the mammals of South-East Asia. New Holland Publishers Ltd.

Freeman, P. W. (1995). Nectarivorous feeding mechanisms in bats. Biological Journal of the Linnean Society, 56(3), 439-463.

Frick, W. F., Price, R. D., Heady III, P. A., \& Kay, K. M. (2013). Insectivorous bat pollinated columnar cactus more effectively per visit than specialized nectar bat. The American Naturalist, 181(1), 137-144.

Gaisler, J., \& Chytil, J. (2002). Mark-recapture results and changes in bat abundance at the cave of Na Turoldu, Czech Republic. Folia Zoologica, 51(1), 1-10.

Gentry, A. H. (1974). Flowering phenology and diversity in tropical Bignoniaceae. Biotropica, 6, 64-68.

Hermanson, J. W., \& O'Shea, T. J. (1983). Antrozous pallidus. Mammalian Species, $213,1-8$.

Horner, M. A., Fleming, T. H., \& Sahley, C. T. (1998). Foraging behaviour and energetics of a nectar-feeding bat, Leptonycteris curasoae (Chiroptera: Phyllostomidae). Journal of Zoology, 244, 575-586.

Idris, S. (2011). Durio of Malaysia. Malaysia Agricultural Research and Development Institute.

Junqueira, C. N., \& Augusto, S. C. (2017). Bigger and sweeter passion fruits: Effect of pollinator enhancement on fruit production and quality. Apidologie, 48, 131-140.

Karasov, W. H. (1992). Daily energy expenditure and the cost of activity in mammals. American Zoologist, 32(2), 238-248. 
Kingston, T., Lim, B. L., \& Zubaid, A. (2006). Bats of Krau Wildlife Reserve. Penerbit Universiti Kebangsaan Malaysia.

Krebs, C. J. (1999). Ecological methodology (2nd ed.). Addison Wesley Longman Inc.

Kunz, T. H., de Torrez, E. B., Bauer, D., Lobova, T., \& Fleming, T. H. (2011). Ecosystem services provided by bats. Annals of the New York Academy of Sciences, 1223(1), $1-38$.

Law, B. S., \& Lean, M. (1999). Common blossom bats (Syconycteris australis) as pollinators in fragmented Australian tropical rainforest. Biological Conservation, 91(2-3), 201212.

Lesiński, G., Gryz, J., \& Kowalski, M. (2009) Bat predation by tawny owls Strix aluco in differently human $\square$ transformed habitats. Italian Journal of Zoology, 76(4), 415-421.

Lim, T. K., \& Luders, L. (1998). Durian flowering, pollination and incompatibility studies. Annals of Applied Biology, 132, 151-165.

MacInnis, G., \& Forrest, J. R. K. (2019). Pollination by wild bees yields large strawberries than pollination by honey bees. Journal of Applied Ecology, 56, https://doi. org/10.1111/1365-2664.13344

Marshall, A. G. (1983). Bats, flowers and fruit: Evolutionary relationships in the Old World. Biological journal of the Linnean Society, 20(1), 115-135.

Medellin, R. A., Equihua, M., \& Amin, M. A. (2000). Bat diversity and abundance as indicator of disturbance in Neotropical rainforests. Conservation Biology, 14, 1666-1675.

Medina, A., Harvey, C. A., Merlo, D. S., Vilchez, S., \& Hernandez, B. (2007). Bat diversity and movement in an agricultural landscape in Matoguas, Nicaragua. Biotropica, 39(1), 120-128.

Mokhzani, C. W. (2017, May 13). King of fruit. The Star. https://www.thestar.com.my/ business/business-news/2017/05/13/thechina-factor-in-durian-prices/

Molina-Freaner, F., Cervantes-Salas, M., Morales-Romero, D., Buchmann, S., \& Fleming, T. F. (2003). Does the pollinator abundance hypothesis explain geographic variation in the breeding system of Pachycereus pringlei? International Journal of Plant Sciences, 164, 383-393.

Muchhala, N. (2006). The pollination biology of Burmeistera (Campanulaceae): Specialization and syndromes. American Journal of Botany, 93(8), 1081-1089.

Muchhala, N. (2007). Adaptive trade-off in floral morphology mediates specialization for flowers pollinated by bats and hummingbirds. The American Naturalist, 169, 494-504.

Neo, P. (2019, October 1). King of fruit exports: Thailand retains positions as largest durian exporter. Food navigator-asim. com. https://www.foodnavigator-asia.com/ Article/2019/10/01/King-of-fruit-exportsThailand-retains-position-as-largestdurian-exporter

Papadatou, E., Pradel, R., Schaub, M., Dolch, D., Geiger, H., Ibanez, C., Kerth, G., PopaLisseanu, A., Schorcht, W., Teubner, J., \& Gimines, O. (2012). Comparing survival among species with imperfect detection using multilevel analysis of mark-recapture data: A case study on bats. Ecography, 35, 153-161.

Paull, R. E., \& Duarte, O. (2012). Tropical fruits volume 2 (2nd ed.). Centre for Agriculture and Bioscience International.

Raghuram, H., Singaravelan, N., Nathan, P. T., Rajan, K. E., \& Marimuthu. G. (2006) Foraging ecology of pteropodid bats: Pollination and seed dispersal. In J. L. Zupan, \& S. L. Mlakar(Eds.), Bats: Biology, behavior and conservation (pp177-188). Nova Science Publishers..

Russo, D., Cistrone, L., \& Jones, G. (2007). Emergence time in forest bats: The influence 
of canopy closure. Acta Oecologica, 31(1), 119-126.

Shafie, N. J., Sah, S. A., Latip, N. S., Azman, N. M., \& Khairuddin, N. L. (2011). Diversity pattern of bats at two contrasting habitat types along Kerian River, Perak, Malaysia. Tropical Life Sciences Research, 22(2), 13-22.

Sherwin, H. A., Montgomery, W. I., \& Lundy, M. G. (2013). The impact and implications of climate change for bats. Mammal Review, 43(3), 171-182.

Smith, A. T., \& Xie, Y. (2008). A guide to the mammals of China. Princeton University Press.

Speakman, J. R. (1991). The impact of predation by birds on bat populations in British Isles. Mammal Review, 21(3), 123-142.

Start, A. N. (1974). The feeding biology in relation to food sources of nectarivorous bats (Chiroptera: Macroglossinae) in Malaysia (Unpublished doctoral dissertation). University of Aberdeen, Aberdeen, Scotland.

Start, A. N., \& A. G. Marshall, (1976). Nectarivorous bats as pollinators of trees in west Malaysia. In J. Burley, \& B. T.
Styles (Eds.), Variation, breeding and conservation of tropical forest trees (pp. 141-150). Academic Press.

Stewart, A. B., \& Dudash, M. R. (2017). Flower visiting bat species contribute unequally toward agricultural pollination ecosystem services in southern Thailand. Biotropica, 49(2), 239-248.

Stewart, A. B., \& Dudash, M. R. (2018). Foraging strategies of generalist and specialist Old World nectar bats in response to temporally variable floral resources. Biotropica, 50(1), 98-105.

Stewart, A. B., Makowsky, R., \& Dudash, M. R. (2014). Differences in foraging times between two feeding guilds within Old World fruit bats (Pteropodidae) in southern Thailand. Journal of Tropical Ecology, 30(3), 249-257.

Thavry, H., Cappelle, J., Bumrungsri, S., Thona, L., \& Furey, N. M. (2017). The diet of the cave nectar bat (Eonycteris spelaea Dobson) suggests it pollinates economically and ecologically significant plants in Southern Cambodia. Zoological Studies, 56(17), 1-7.

Willmer, P. (2011). Pollination and floral ecology. Princeton University Press. 